\title{
ELT Master's Programmes in Thailand: Focused Areas and Research Trends
}

\author{
Athip Thumvichit \\ Ramkhamhaeng University \\ Correspondence concerning this article should be addressed to Athip Thumvichit, Ramkhamhaeng \\ University, 2086 Ramkhamhaeng Rd, Hua Mak, Bang Kapi District, Bangkok 10240. \\ E-mail: athip.t@rumail.ru.ac.th
}

\begin{abstract}
The increasing demand for competent users of English and qualified English teachers has accelerated the growth of graduate programmes in English language teaching (ELT). In Thailand, ELT master's programmes have been serving as a training ground for Thai English teachers for decades. This study explores the focused areas and research trends of Thai ELT master's programmes. The analyses involved ten ELT master's programmes offered by ten different universities and 201 master's theses submitted between the years of 2014 and 2018. Foundation and core courses were categorised into twelve content areas. The findings show that teaching and research methodology courses were the most common areas, indicating that the programmes were not only pedagogical but also research-oriented. In consistence with the international trends of ELT research, the Instructional effects research area still prevails. The number of studies on Assessment and Curriculum/Programme is relatively low compared with the number of courses in such areas. Also discussed are considerations for programme management, lecturers, and students. It is also recommended that all the courses offered be treated as a gateway to research opportunities in addition to teaching practice and professional practice improvement.
\end{abstract}

Keywords: English language teaching, English teachers, master's programmes, master's theses, research trends

\section{Introduction}

English Language Teaching (ELT) master's programmes in Thailand were established to strengthen qualifications and career pathways of those entering or already employed in English language education. The programmes are considered a concentrated route for professional English teachers, especially ones aiming for advanced skills and knowledge in the field of pedagogy. The programmes are also considered a stepping stone to professional development and a gateway to a teaching career at the tertiary level. In this sense, ELT master's programmes are now serving as a training ground for Thai English teachers and even for those who are pursuing other English-related careers. As English becomes more important and pervasive, ELT master's programmes in Thailand are growing more diverse. Despite the increasing number, diversity, and benefits of ELT master's programmes, the programmes as a whole have not yet been comprehensively explored. With the absence of upto-the-minute literature devoted to the progress of ELT at the graduate level, there is a paucity of understanding surrounding areas of focus and research trends in ELT master's programmes around the country. By gaining insight into the currently research trends and areas of focus, ELT scholars and programme management can be better informed about the present state of affairs in the ELT community (Lin \& Chen, 2010). Addressing such issues also provides a better understanding of how to move the ELT community forward (Abdel Latif, 2018).

Considering the importance of ELT masters' programmes, as the first part of a larger effort ${ }^{1}$ to explore various aspects of these programmes, this study is devoted to investigating areas of focus and research trends. Exploring these two areas will highlight the knowledge fields and research areas that have been emphasised and underemphasised in ELT master's programmes, leading to calls for changes to improve the programmes.

\footnotetext{
${ }^{1}$ The other part of this project explores reasons for attending ELT master's programmes and crucial factors influencing the choice of university and programme (Thumvichit, 2020).
} 


\section{From English Language Education Reforms to the Establishment of ELT Programmes}

The Thai government promulgated the National Education Act (NEA) of 1999 to improve overall educational quality. One of the main areas of focus was tertiary education with an emphasis on internationalising it and making English as a medium of instruction standard practice. Such an attempt accelerated the growth of international programmes and the emergence of various English-related courses (Kaur et al., 2016). Proposed by the Ministry of Education (MoE) to replace the 2001 Basic Education Core Curriculum (BEC), the 2008 BEC was explicitly crafted to address the demands of globalisation, making English an essential language. It suggested that language learning should concentrate not only on communicative goals, but also culture, relationships with other disciplines, and relationships among communities. To align with the proposed ideas and the growing importance of English in the global arena, the stimulation of English language education came in the form of accredited international schools, English programmes (EPs) and bilingual programmes (BPs) at schools, and international programmes at higher education institutions.

Additionally, the MoE realised the importance of graduate programmes as a route to professional development and career advancement, promoting the establishment of university language institutes to fulfil the rising need for English language training for a wide variety of purposes ranging from general to professional communication to English teacher development. The $21^{\text {st }}$ century has witnessed the considerable growth of the ELT graduate community in Thailand. ELT graduate programmes have now become diverse in focus and variously named. Some of them are called English Language Teaching (ELT), and others operate under the widely used name Teaching English to Speakers of Other Languages (TESOL). One programme that sets itself apart from others is named Applied Linguistics for English Language Teaching (ALELT). In response to the current status of English, there are also programmes named Teaching English as an International Language (TEIL) and Teaching English as a Global Language (TEGL), addressing the intercultural aspects of ELT. Unlike other major fields, the master's degree in ELT is offered as either a Master of Arts (MA) or Master of Education (MEd). Although various types of ELT graduate degrees are offered (e.g., certificates, master's degrees, doctoral degrees), the master's degree has tended to receive greater attention than others because, in general, it is the minimum requirement for a tertiary teaching position and the programme's duration is only two years on average.

\section{Research into ELT Master’s Programmes}

Many studies have been conducted to develop a better understanding of ELT programmes. Hasrati and Tavakoli's (2015) work draws on interview and questionnaire data to explore how globalised contexts of higher education affected MA TESOL programmes in the UK. They found that globalisation has brought more international students to the programmes and brought about the need to modify the programmes' curricula and content. US survey studies reported that approximately $40 \%$ of the students enrolling in MA TESOL programmes in the US (England \& Roberts, 1989) and as many as $90 \%$ in some US universities between the late 80s and 2001 (Brady \& Gulikers, 2004) were L2 users of English. Since English-speaking countries are perceived to be a reliable destination for international students, topics related to international students' experiences in English-related graduate programmes have received tremendous attention from language scholars as they contribute immensely to the programmes' development. There have been numerous studies focusing on international students' experiences of ELT-related master's programmes in top higher education destination countries: the US (e.g., Baecher, 2012; Tseng, 2013), the UK (e.g., Copland \& Garton 2012; Fordyce \& Hennebry 2013; Schartner \& Young, 2015), Australia (e.g., Hughes \& Bruce, 2013; Phakiti \& Li, 2011), and New Zealand (e.g., Li \& Tin, 2013). While many prior studies focused on a single university or a particular group of universities, Copland et al. (2017) conducted a national-scale study focusing on ELT master's programmes in the UK. In that study, several aspects of ELT master's programmes were explored: the availability of the courses, modes and formats, target students, enrolment decisions, and students' expectations. Involving nearly all of the ELT master's programmes in the UK, the findings of this study can represent various aspects of ELT master's programmes in the UK.

Regarding content areas covered in ELT master's programmes, Stapleton and Shao's (2018) large-scale study reports on a survey of 241 MA TESOL programmes offered in 16 countries. In this study, courses offered in the programmes were examined for their coverage and prevalent knowledge fields. It revealed a wide range of knowledge fields not limited to the teaching and learning of English. That is, courses with an emphasis on society, culture, sociolinguistics, literature, and language arts were also covered in the programmes. It was also 
found that the most common knowledge field was Teaching methods/issues, followed by Elements of linguistics (e.g., lexis, phonetics, phonology, and semantics). Apart from the findings, that study provided insights into a certain community of ELT graduate programmes.

Despite the growth of the ELT graduate community, the rising demand for qualified English teachers and competent English users at professional levels, and the growing body of research on ELT master's programmes in the context of top education destination countries, there has been an absence of research committed to exploring ELT master's programmes in Thailand as a whole. The current study is, therefore, a timely response to this shortage and can trigger local researchers' interest in the Thai ELT community. Although this study does not directly reflect the current state of the global community of ELT graduate programmes that are growing rapidly along with the importance of English, it commits to moving this community forward by observing what the programmes have to offer to improve teaching practice, enhance research skills, and expand opportunities.

\section{Previous Studies on Trends of Language Teaching Research}

Over the past decade, a growing interest in ELT research among language scholars can be observed. Lin and Cheng (2010) investigated the prevalent research contexts and research areas of master's theses in Taiwan universities produced between 2003 and 2007. To identify the prevalent research areas, they adopted the list of content areas created by the TESOL International Association in 2009. Their findings suggested that the most preferred was Language skills followed by Teaching methods, and the majority of studies were conducted on the secondary education platform, which concurs with the programme objectives and aspects of the courses. Employing a similar list of research areas to categorise research papers, Kirmizi (2012) investigated the research trends of master's theses submitted in universities in Turkey between 2006 and 2011. Identically, Language skills and Teaching methods remained at the top of the list. Master's programmes, however, were not the only source of data for the identification of research trends. Tůma and Píšová (2013) drew on doctoral dissertations defended in the Czech Republic and abroad between 2006 and 2012. Instead of adopting the previously proposed categorisation framework, they employed thematic analysis to outline the research categories. The findings showed that Management of teaching/learning processes was the most prevalent category. However, this does not mean that the findings of Tủma and Píšová's (2013) study were entirely in line with those of aforementioned studies because Management of teaching/learning processes tended to incorporate a broader range of research themes than Language skills in the TESOL list, which concerns only different language skills. A more extensive study by Bani-Khaled's (2012) pointed to trends over four decades covering the period from 1974 to 2010. In that study, a corpus of 550 master's theses and doctoral dissertations was compiled. Pedagogy/ Methodology was ranked the most researched area of research with over 30\% concerning teaching and teaching methods. It is interesting to learn that pedagogy and teaching methods were the most selected areas, even in non-teaching programmes.

Besides master's theses and doctoral dissertations, published articles also served as data in studies on ELT research trends. Wenfeng and Gao (2008), for example, investigated the research areas of research output on English language education in China. A corpus of 81 articles published between 2001 and 2006 in 24 international journals was compiled. The findings indicated that English used in China had more articles than others. This category covers a range of research areas including the development of English as a foreign language in China, varieties of English, and linguistic analyses of English used in China. Unlike master's theses and doctoral dissertations, internationally published articles tended to seek an understanding of how Chinese influenced the development and use of English in China, rather than teaching elements. Some studies were designed to investigate the research trends of a single journal. Stapleton and Shao (2017), for example, unveiled the research trends of the 359 articles published in the Language Teaching Research journal during the journal first's 20 years. Instructional effects was a more common theme than others. Although the journal invited a vast range of topics, teaching-related topics remained the most popular.

When the scope of research is restricted to the 'teaching' of a particular language, researchers can generate a list of research areas used specifically to categorise 'teaching' research. Recently, Abdel Latif (2018) proposed a list that emphasises the teaching elements of ELT research. All nine research areas presented in the list are related to the teaching and learning of English because the study attempted to identify the research trends of published research only in the field of ELT. To this end, unlike previous studies, the researcher did not add research areas that were not related to the teaching of English. In addition to identifying research areas, which 
was the main focus of the study, the researcher also identified the research methods and designs of the studies as well as the contexts in which the studies were conducted. As for the research methods and designs, each research article was labelled either 'experimental' or 'non-experimental', and either 'quantitative', 'qualitative', or 'mixed'. The researcher proposed a set of research contexts covering a wide variety of educational stages ranging from the kindergarten level to the tertiary level to non-award programmes, leading to a firm understanding of the contexts in which the studies were conducted. Nevertheless, research trends undergo changes over time and thus the findings can represent only a snapshot of research trends. In this sense, the current study serves as a picture of the current state of ELT education at the graduate level in Thailand, investigating research trends to better understand research focuses and directions, and highlight the dearth of research on some knowledge fields.

\section{Methodology}

\section{Identifying ELT Master's Programmes in Thailand}

First, I browsed through the list of higher education institutions provided by the Office of the Higher Education Commission (OHEC) (www.mua.go.th) to identify all higher education institutions and all curricula approved between the years of 2012 and 2018. Under the supervision of the OHEC, 156 higher education institutions were identified. I read through the list to obtain the names of English-related master's programmes. Since this study focuses purely on English teaching programmes, those offering an English-related degree that was not entirely devoted to teaching (e.g., Applied Linguistics, English as an International Language, English for Specific Purposes) were excluded. In addition, the programmes that had ceased recruiting students were also excluded. Accordingly, I contacted the programme coordinators to ensure the latest status of the programmes before proceeding. I found that some programmes were temporary, if not permanently, closed due to the shortage of applicants and/or qualified lecturers. After several rounds of screening, ten programmes offered by ten different universities were identified. Six of them were offered under the MA degree, and the rest were offered under the MEd degree. The selection of the programmes, therefore, renders the results more representative of focused areas and research trends of ELT master's programmes in Thailand. To maintain the ethical standards, the programme titles and the names of the universities are not disclosed. Throughout this paper, therefore, the codenames ELTP1 to ELTP10 are used to refer to the programmes.

\section{Analysing Focused Areas}

\section{Courses Offered in ELT Master's Programmes}

To capture the focused areas, this study drew on taught courses offered in the programmes. In general, there were three types of courses: foundation courses, core courses, and elective courses. Foundation courses are courses that are required prior to or alongside core courses, all of which are compulsory for all students. Foundation courses generally aim to prepare students for graduate-level study and studies in the field of education. Foundation courses under the ELT master's programme come in the form of English skills development or non-English-related educational principles. However, as indicated in curriculum documents, some foundation courses can be waived if students meet certain requirements, such as satisfactory results of a prescribed English test. Elective courses, on the other hand, were treated as choices. Therefore, all the elective courses were excluded from this analysis. In this regard, all foundation and core courses of each programme were collected for the analysis.

The programmes tended to offer two sets of courses: one for the thesis plan and one for the non-thesis plan. In some programmes, the two sets were slightly different as the non-thesis plan, also known as Plan B, required more course credits than the thesis plan, also known as Plan A. In ELTP8, for example, Plan B required six more core course credits than Plan A. Non-thesis students were offered some courses that were completely absent in Plan A. Thus, to align with the other focus of this study, namely research trends of master's theses, only courses that were offered in Plan A were analysed.

\section{Data Analysis}

The foundation and core courses were categorised into different focused areas in ELT, employing thematic analysis, which helps identify a distinctive set of themes representing a particular dataset. To do so, course descriptions were read through to identify the content and scope of the courses, both of which were used for 
assisting categorisation of themes. The courses with the same or similar content areas were convened, after which distinct themes emerged representing different content areas. The findings are discussed for insight into the overall focused areas of ELT master's programmes in Thailand.

\section{Analysing Research Trends}

\section{Identifying Theses in ELT Master's Programmes}

This study draws on ELT master's theses made publicly accessible between 2014 and 2018 from ELT programmes. Master's theses and doctoral dissertations are normally not published in external academic journals but rather are available on library databases. Therefore, these databases were used to generate data for the analysis. After locating the library websites, I used built-in search engines to gain access to the full-text files of the theses. The built-in search engines were configured for searching master's theses submitted between 2014 and 2018. The rationale behind choosing these years was that they were the five most recent years and that they would reflect the most recent research trends. Since the libraries allow public access, the full-text files were downloaded and stored on a computer. In cases where the library's built-in search engine had no features that could help locate potential theses, librarians were contacted for support. However, some recently completed theses were not yet made publicly accessible, especially those approved in 2018. To this end, to avoid violating university copyright policies, only theses that were available on the library databases at the time of conducting this study were collected for the analysis. However, there were a few theses that were excluded because of the absence of full-text files. Visiting all the library databases yielded a corpus of 201 theses.

\section{Data Analysis}

This study employed Stapleton and Shao's (2017) list of research focuses as a starter, which comprised 13 areas: (1) Instructional effects, (2) Teacher cognition, (3) Exploratory practice, (4) Teacher education, (5) Learner behaviors, (6) Learner cognition, (7) Theoretical essays, narratives, and descriptions, (8) Teacher practices, (9) SLA mechanism, (10) Instructional materials, (11) Assessment, (12) Curriculum and program development, and (13) Review, surveys, meta-studies. The rationale behind this selection was that their framework covered a broad range of topics and clear-cut descriptors were provided, making adoption and adaptation plausible. However, the list was subject to modification. As coding proceeded, the extended list of research areas was revised until reaching the final scheme that could cover all the thesis titles. To handle the subjective nature of coding, apart from the researcher, another coder with considerable experience in teaching English and supervising ELT students was invited to ensure the reliability of the coding protocol. The external coder was given a modified list of eleven research categories with examples for each category. A short trial session was held to secure a comprehensive understanding of each category. Owing to the labour-intensiveness of coding, the external coder was assigned to code only $50 \%$ (100 theses) of the theses. The inter-coder agreement was measured with a chance-corrected agreement measure, Cohen's Kappa coefficient, $\kappa$, and the percentage to agreement. A $\kappa$ value of 9.33 was generated with an agreement of $95 \%$. Once the two coding systems were finalised, the theses were categorised based on the primary research aim. The main body of the papers were reviewed, in addition to the titles and abstracts, as that part of the paper provided information regarding the actual research objective of the theses. The frequency count of each research area was also generated to address the differences between research areas.

\section{Results and Discussion}

\section{Areas of Focus}

Analysing the themes of taught courses yielded twelve content areas (see Table 1). The number of compulsory courses varied from programme to programme ranging from five to 14 courses as some programmes tended to add more weight to elective courses giving students more freedom to choose courses that suited their goals and interests. While most of the areas presented here are language-related, if not English-related, there was an area that did not focus on language but was offered to prepare students for studying advanced content in the field of education. Offered in five programmes, General teaching/education courses covered a broad range of teaching practices and education, including pedagogical sciences, principles of education, educational management, teacher professional development, educational psychology, and educational philosophy. Students were required to take these courses prior to or at the same time as core courses. In addition to General teaching/ 
education, General language studies aimed to prepare students for language elements in the ELT programmes; however, this type of course did not specifically target any particular ELT elements but rather addressed the general foundation of language studies.

In some programmes, foundation courses could be offered as English proficiency development, which aimed to improve students' English language skills essential for graduate-level work such as reading scholarly articles, academic writing, and giving an academic presentation. Nevertheless, English proficiency development courses were not always compulsory. In ELTP2, for example, students who were L1 users of English or could demonstrate sufficient English language proficiency were able to waive such courses. English proficiency development was one of the most preferred areas, with twelve courses identified in six programmes. However, these courses were omitted in some programmes. ELTP1, ELTP3, ELTP6, and ELTP9 did not offer any English skills courses but rather required all applicants to demonstrate a certain level of English proficiency before applying. Qualified results of English proficiency tests such as 79 for TOEFL IBT and 6.5 for IELTS were typically used as one of the admission requirements to ensure readiness for graduate-level work and meet the standard for English-related programmes. Apart from scores on universal standardised tests, those of some in-house English proficiency tests given by universities in the country are also accepted for some programmes these days.

Table 1

Foundation and core courses offered in ELT master's programmes

\begin{tabular}{|c|c|c|c|c|c|c|c|c|c|c|}
\hline \multirow{2}{*}{ Areas } & \multicolumn{10}{|c|}{ Number of Courses } \\
\hline & ELTP1 & ELTP2 & ELTP3 & ELTP4 & ELTP5 & ELTP6 & ELTP7 & ELTP8 & ELTP9 & ELTP10 \\
\hline Language teaching methodology & 1 & 1 & 1 & 2 & 2 & 2 & 1 & 1 & 1 & 1 \\
\hline Research methodology & 1 & 1 & 1 & 1 & 1 & 1 & 2 & 2 & 2 & 1 \\
\hline English proficiency development & & 1 & & 1 & 2 & & 4 & 3 & & 1 \\
\hline General teaching/education & & & 2 & & 3 & & 3 & 2 & & 1 \\
\hline Language assessment/evaluation & 1 & 1 & 1 & 1 & 1 & 1 & 1 & 1 & & \\
\hline Language learning & 1 & 1 & & 1 & 2 & 1 & 1 & & 1 & \\
\hline Applied linguistics & & & & 4 & & & & 1 & 1 & 1 \\
\hline $\begin{array}{l}\text { Language course/curriculum } \\
\text { development }\end{array}$ & & 1 & 1 & & 1 & 1 & & & & \\
\hline $\begin{array}{l}\text { Technology for teaching and } \\
\text { learning }\end{array}$ & & & & & 1 & & & 1 & & 1 \\
\hline Cultural aspects & & 1 & & & 1 & & & 1 & & \\
\hline Materials development & 1 & & & & & & 1 & & & \\
\hline General language studies & 1 & & 1 & & & & & & & \\
\hline
\end{tabular}

As for content areas, Language teaching methodology was one of the most preferred areas with 13 courses offered, concurring with Stapleton and Shao's (2018) report on the most common knowledge fields of MA TESOL programmes in 16 countries. Offered in all the programmes, this content area covered a range of content: language teaching approaches, principles, and theories. Although some courses in this category were vaguely named, the course descriptions did indicate that, to some degree, they focused on at least one of the elements mentioned above. Another most preferred content area was Research methodology. This content area covered various dimensions of research including but not limited to principles, designs, procedures, instrumentation, data collection, and sampling. While most programmes tended to offer one research course that attempted to highlight various research elements, ELTP2 offered a selection of research courses: quantitative, qualitative, and general methodology. That is, students chose only one of the research courses that they found relevant. Despite being offered as options, these courses were considered core courses, as noted by the curriculum document. Up to that point in my research, Language teaching methodology and Research methodology were not omitted from any of the programmes, as the former focuses on teaching practice and the latter focuses on research elements, making them key components of ELT master's programmes.

Language assessment/evaluation and Language learning were also highly preferred with eight courses identified in eight and seven programmes respectively. Assessment has been one of the essential constituents of education, playing a crucial role in the teaching and learning process, and ELT is no exception. Language 
assessment/evaluation deals with a wide variety of topics related to language testing, assessment, and evaluation. The availability of language assessment courses is in response to scholarly calls for the promotion of language assessment literacy amongst teachers, assessment tool developers, policymakers, and even students (e.g., Baker, 2016; Deygers \& Malone, 2019). ELTP9 and ELTP10, however, offered this content area as elective courses. While teaching has become the key focus of the programmes, learning has also received considerable attention from programme developers. Seven of the ten programmes offer courses focusing specifically on language learning elements. Language learning covers any content area related to the learning and acquisition of a second or foreign language. Language acquisition tends to be the most popular course in this content area as it addresses fundamental aspects of how one successfully acquires a (second or foreign) language. Another preferred content area is Language curriculum development, with four courses identified in four programmes. This content area moves beyond the teaching and learning aspects to the curriculum level of language education. It is undeniable that, apart from teaching and administrative duties, English teachers are often involved with course and curriculum development, and this aspect of English teaching renders this content area essential.

There was no other content areas that appeared in more than three programmes. The rest of the taught course credits were devoted to content areas in which the programmes specialised. For example, a content area that yielded the identity of ELTP2 was Cultural aspects. In ELTP2, several cultural-related courses were offered as core and elective courses because it specialised in teaching English in global contexts, which involves topics such as English as a lingua franca (ELF), the influence of culture on ELT, and different varieties of English.

Despite being committed to the pedagogical aspects of English, some of the programmes reserved some credits for Applied linguistics with seven courses identified across the programmes. This content area allows students to explore the micro-level of language and ways to apply different types of linguistic elements (e.g., phonetics, syntax, semantics, pragmatics) for practical purposes. Nevertheless, some content areas deemed vital in ELT did not receive much attention from programme developers. Notwithstanding urgent calls for the incorporation of technology into ELT, technology courses have still not been made compulsory in most ELT master's programmes in Thailand. Only three compulsory technology-related courses were noted, all of which tended to focus on the roles and applications of information and communication technology (ICT) in ELT. Materials development is another content area that deserves more attention from programme developers. Like curriculum development, designing and selecting instructional materials are essential for English teachers at all levels. However, only two core courses on Materials development were found, both of which emphasised not only ELT materials design but also evaluation, analysis, and adaptation.

\section{Research Trends}

The research categories presented in this study are different from those of Stapleton and Shao (2017) because a new boundary for all the research categories was needed in response to the distinctiveness of the dataset. Thus, one main coding scheme was proposed for categorising the theses into different research areas and another for categorising theses that fell into the Instructional effects category into different target areas that researchers attempted to improve.

Table 2

Research areas of ELT master's theses

\begin{tabular}{|c|c|c|c|}
\hline Research Area & Example & No. of Theses & $\%$ \\
\hline Instructional effects & $\begin{array}{l}\text { effects of instructional approaches on language skills, performance, and } \\
\text { cognitive aspects }\end{array}$ & 102 & 50.7 \\
\hline Learner cognition/practice & $\begin{array}{l}\text { learners' beliefs, attitudes, self-reflection, processing, difficulties, } \\
\text { awareness, and learning strategies }\end{array}$ & 24 & 11.9 \\
\hline Linguistic analysis & discourse analysis, genre analysis, lexical analysis, and corpus linguistics & 17 & 8.4 \\
\hline Teacher cognition/practice & $\begin{array}{l}\text { teachers' beliefs, attitudes, self-perceived, senses, teaching strategies, and } \\
\text { teaching styles }\end{array}$ & 16 & 7.9 \\
\hline Culture/Identity & $\begin{array}{l}\text { intercultural communication, World Englishes, learner identities, and } \\
\text { gender }\end{array}$ & 11 & 5.4 \\
\hline
\end{tabular}




\begin{tabular}{|c|c|c|c|}
\hline Research Area & Example & No. of Theses & $\%$ \\
\hline English for professionals & professional communication and professionals' needs of English & 8 & 3.9 \\
\hline Influential factors & $\begin{array}{l}\text { factors affecting comprehension, causing willingness, and facilitating } \\
\text { learning }\end{array}$ & 8 & 3.9 \\
\hline Assessment & test development, test evaluation, and washback effects & 7 & 3.4 \\
\hline Curriculum/Programme & programme evaluation, curriculum design, and lesson development & 4 & 1.9 \\
\hline Instructional materials & materials development and textbook evaluation & 3 & 1.4 \\
\hline Teacher education & $\begin{array}{l}\text { pre- and in-service teacher practice, the teaching profession, and teacher } \\
\text { professional development }\end{array}$ & 1 & 0.4 \\
\hline Total & & 201 & \\
\hline
\end{tabular}

Eleven research areas were identified, covering a wide variety of English-related topics. Table 2 shows that Instructional effects dominated ELT research conducted in master's programmes in Thailand with $50.7 \%$ of the theses. Instructional effects covered studies that primarily focused on the influences of instructional approaches on students' skills, performance, and cognitive aspects. This finding concurs with previous thesis research trends in Taiwan (Lin \& Cheng, 2010) and Turkey (Kirmizi, 2012) in that instructional approaches and language skills were the most researched in the field. The dominance of this research area also existed in the top international publication platforms such as the Language Teaching Research journal, in which almost half of the articles focused on the effects of instructional approaches (Stapleton \& Shao, 2017). This figure aligns well with that of the taught courses under Language teaching methodology, which was the most common content area of the programmes.

While Stapleton and Shao's (2017) study focused on instructional approaches, which were further categorised into sub-categories, the current study emphasised target skills, performance, and cognitive aspects that researchers attempted to investigate. Thus, the theses under Instructional effects were further categorised into nine sub-categories (see Table 3). Reading was the most researched target area with $21.5 \%$ of the theses, followed by Writing and Speaking. Such findings align well with the ELT research trends in Egypt uncovered by Abdel Latif's (2018) study finding that, among the four skills of language, reading was the most researched area, followed by writing, speaking, and listening respectively. Integrated skills and Cognitive aspects also received some attention with 13 (12.7\%) theses each. Studies on Integrated skills attempt to improve two or more language skills simultaneously (e.g., speaking and listening, reading and writing, communicative skills). On the other hand, Cognitive aspects cover studies that explore learner cognition towards instructional approaches (e.g., learner's motivation, attitudes, beliefs, satisfaction, willingness). However, Vocabulary and Grammar were hardly researched, compared with the four skills of language, with only nine and seven theses identified respectively. Despite being one of the four language skills, Listening, as an isolated skill, was least researched; however, listening and pronunciation were often treated as an integrated area along with speaking, turning them into Integrated skills rather than Listening or Pronunciation.

Table 3

Sub-areas of Instructional effects

\begin{tabular}{lcc}
\hline \multicolumn{1}{c}{ Sub-areas } & No. of Theses & \% \\
\hline Reading & 22 & 21.5 \\
Writing & 18 & 17.6 \\
Speaking & 16 & 15.6 \\
Integrated skills & 13 & 12.7 \\
Cognitive aspects & 13 & 12.7 \\
Vocabulary & 9 & 8.8 \\
Grammar & 7 & 6.8 \\
Listening & 2 & 1.9 \\
Pronunciation & 2 & 1.9 \\
\hline Total & $\mathbf{1 0 2}$ & \\
\hline
\end{tabular}

Apart from Instructional effects, the other half of the theses covered a range of topics in the remaining research areas. The theses that fell into the rest of the research areas were not done in an experimental manner but 
rather aimed to explore, develop, or evaluate particular English-related elements. The second most researched area was Learner cognition/practice with 24 (11\%) theses, followed by Linguistic analysis with 17 (8.4\%) theses, and Teacher cognition/practice with 16 (7.9\%) theses identified. Learner cognition/practice and Teacher cognition/ practice cover a broad scope of cognitive aspects and practices of learners and teachers (e.g., beliefs, attitudes, awareness, learning/teaching strategies). These two research areas differ from Cognitive aspects under Instructional effects in that they both were not treated as experimental but rather as exploratory research.

Unlike the aforementioned research areas, Linguistic analysis explores a particular linguistic feature in a specific text type such as research articles, master's theses, essays, songs, news articles, comics, or email transactions. This research area has to do with various text analytical approaches such as discourse analysis, genre analysis, lexical analysis, and corpus linguistics. Despite not being offered as a standalone compulsory course, these text analytical approaches were still highly researched. Culture/Identity was another topic that was researched in more than ten theses. This research area deals with cultural influences on English and identity issues related to ELT. Topics including, but not limited to, intercultural communication, World Englishes, learner identities, and gender fall into this category. The field of ELT is not limited to teaching and learning in the contexts of formal education. Some students also researched English in other professional settings. Studies on English for professionals deal with ELT and the use of English in professional contexts other than formal education. In this research area, a variety of careers researched by students were identified such as train conductors, customs personnel, Royal Army officers, health service professionals, and diving instructors. Some students chose Influential factors as their research topics. This covers any studies that aimed at exploring factors that influence teaching and learning.

Some research areas did not match the number of compulsory courses offered in the programmes. Only seven theses fell into Assessment, which, as its name suggests, covers any topic related to exams and tests, even though almost all of the programmes offered compulsory assessment courses. Such an imbalance can also be seen in the case of Curriculum/Programme, considering the number of curriculum courses offered, and in the case of Teacher education, considering the nature of the programmes. Instructional materials did not receive much attention with only three theses identified despite the vital role teaching materials play in language classrooms. English textbooks, for example, are considered an integral component of any English classroom lesson (Cortazzi \& Jin, 1999; McGrath, 2016; Richards, 2006; Tomlinson, 2008), and materials evaluation is regarded as a global issue (McGrath, 2016; Tomlinson \& Masuhara, 2017) leading to a growing body of international literature on textbook evaluation along with materials development.

\section{Conclusion}

Although the current study was conducted in a descriptive manner, the ten programmes reviewed in this study rendered results more representative of the areas of focus and research trends of ELT master's programmes in Thailand. Exploring each of the ten programmes revealed a huge variation in the courses deemed compulsory. Language teaching methodology as a standard content area indicated that the ELT master's programmes nationwide have emphasised instructional approaches and strategies. As Stapleton and Shao (2018) argued, Richards's (2008) claim that master's programmes generally focus on language acquisition rather than language teaching may not be entirely true, at least in the Thai context. The current study confirms that even at a national scale, pedagogical content still dominates master's research in Thailand. This trend is subject to change, but as of now, this content area has received considerable attention from international and Thai ELT master's programmes. Another prime focus of Thai ELT master's programmes is Research methodology. Although the research content area is not widely featured in international ELT master's programmes (Stapleton \& Shao, 2018), it serves as a central focus in Thai ELT master's programmes along with the pedagogical content area. The programmes are well-suited for both classroom teachers and those who are seeking a teaching position at a higher education institution, which often requires research skills and experience. This also implies that the programmes have been adjusted to the growing demand for qualified English teachers at all stages of education and responded to the call for more research content. In this sense, ELT master's programmes in Thailand are aimed at preparing current and prospective English teachers for both classroom instruction and research so as to make them strong candidates for any English teaching position. Such findings, nevertheless, do not conform to degree-type programmes. Several higher education institutions in the US provide the benchmark for how to 
ascertain the difference between an MEd and MA degree. The Faculty of Education at the University of Kansas, for example, provides an MA degree that is scholarly-oriented, with an emphasis on sophisticated field knowledge (e.g., theories, procedures, research); on the contrary, their MEd degree is practice-focused, focusing on teaching practices (e.g., instructional approaches, material designs, curriculum development). While the MA degree prepares students for a teaching career in higher education institutions and further education, the MEd degree is suitable for licensed teachers who hope to improve their teaching practices or move into an administrative role. However, such rules may not apply to Thai ELT master's programmes. Upon browsing through the compulsory courses offered, it can be concluded that the MEd and MA degrees in teaching English are not treated differently. They did not seem to be one or the other but rather both were career- and researchoriented.

Dominating international ELT research for over two decades (Stapleton \& Shao, 2017), Instructional effects research area is the most preferred topic in Thailand as well. The growth of this research area in ELT master's programmes may be influenced by students' experience as classroom practitioners and the fact that classroom teachers are expected to implement new teaching methods, even though there is an abundance of other topics to choose from. The imbalance between compulsory courses and research options for theses was noticeable. The number of studies focusing on assessment was relatively low, especially when considering the number of compulsory assessment courses offered in the programmes and the importance of assessment in the teaching and learning process. The areas of curriculum planning, instructional materials, and teacher education also suffered from a shortage of research.

In closing, this study casts light on the current situation with regard to ELT master's programmes in Thailand in terms of areas of focus and research trends. The findings presented here suggest issues that require the attention of programme management, lecturers, and students. Since ELT deals with various aspects of education, content and research areas should not be limited to classroom instruction or an investigation of the efficacy of instructional approaches. I would encourage programme management and lecturers to treat other content areas (e.g., assessment, curriculum development, materials development) as a gateway to new research opportunities. Students should be exposed to a wide variety of topics and encouraged to explore research areas relevant to their practices. International trends in ELT and ELT research should be reviewed from time to time to keep community members up to date and move the community forward. This study was conducted in response to the absence of literature on Thai ELT master's programmes and the first step towards the understanding of Thai ELT master's programmes as a teaching, learning, and research community.

Like any research, this study has its limitations that need to be addressed. The scope of this study was limited to English teaching programmes; however, there are several other language-related programmes (e.g., Applied Linguistics, Linguistics, English for as Specific Purposes, English as an International Language) that can be explored for a better understanding of the ELT graduate community as they can also reflect areas of focus, research trends, and other aspects of ELT. Future research should consider reviewing such programmes to obtain more conclusive findings. Although this study claimed that its findings indicated research trends from the last five years, some recently submitted master's theses were not collected because they were not yet available for public access, especially those submitted in late 2018. With all the theses submitted between the years of 2014 and 2018, the findings would have been more conclusive. The ELT master's programmes that were omitted in this study because of temporary closure should be considered by future researchers once they resume operation. Considering the growing importance of ELT master's programmes, future research should also consider exploring other aspects such as challenges faced by programme management, student expectations, and student satisfaction as they contribute immensely to the development of the programmes and the ELT community.

\section{Acknowledgements}

This work was financially supported by the Faculty of Education, Ramkhamhaeng University. My sincere gratitude goes to the external coder for participating in the inter-rater reliability evaluation. I deeply thank the anonymous reviewers and the editorial team for the careful reading and insightful suggestions. 


\section{References}

Abdel Latif, M. M. (2018). English language teaching research in Egypt: Trends and challenges. Journal of Multilingual and Multicultural Development, 39(9), 818-829. https://doi.org/10.1080/01434632.2018.1445259

Baecher, L. (2012). Feedback from the field: What novice preK-12 ESL teachers want to tell. TESOL Quarterly, 46(3), 578-588. https://doi.org/10.1002/tesq.43

Baker, B. (2016). Language assessment literacy as professional competence: The case of Canadian admissions decision makers. Canadian Journal of Applied Linguistics, 19(1), 63-83.

Bani-Khaled, T. A. (2012). Jordanian English language research: A meta-analysis. International Journal of Humanities and Social Science, 2(14), 55-66.

Brady, B., \& Gulikers, G. (2004). Enhancing the MA in TESOL practicum course for nonnative English-speaking student teachers. In L. D. Kamhi-Stein (Ed.), Learning and teaching from experience: Perspectives on non-native English-speaking professionals (pp. 206-229). The University of Michigan Press.

Copland, F., \& Garton, S. (2012). Life after online learning. In L. England (Ed.), Online language teacher education: TESOL perspectives (pp. 64-77). Routledge.

Copland, F., Viana, V., Bowker, D., Moran, E., Papageorgiou, I., \& Shapira, M. (2017). ELT master's courses in the UK: Students' expectations and experiences. British Council. https://englishagenda.britishcouncil. org/continuing-professional-development/teacher-educator-framework/taking-responsibility-ownprofessional-development/elt-masters-courses-uk-students-expectations-and-experiences

Cortazzi, M., \& Jin, L. X. (1999). Cultural mirrors: Materials and methods in the EFL classroom. In E. Hinkel (Ed.), Culture in second language teaching (pp. 196-219). Cambridge University Press.

Deygers, B., \& Malone, M. E. (2019). Language assessment literacy in university admission policies, or the dialogue that isn't. Language Testing, 36(3), 347-368. https://doi.org/10.1177/0265532219826390

England, L., \& Roberts, C. (1989, March 7-11). A survey of foreign students in MA-TESOL programmes [Paper presentation]. The Annual Meeting of the Teachers of English to Speakers of Other Languages, San Antonio, TX. https://files.eric.ed.gov/fulltext/ED306764.pdf

Fordyce, K., \& Hennebry, M. L. (2013, September 6). An investigation to the degree of alignment between student expectations and actual experiences on a one-year master's in TESOL at a UK university [Paper presentation]. The BAAL Conference, Edinburgh.

Hasrati, M., \& Tavakoli, P. (2015). Globalisation and MA TESOL programs in the UK. Higher Education, 69(4), 547565. https://doi.org/10.1007/s10734-014-9790-5

Hughes, H. E., \& Bruce, C. S. (2013). International students' experiences of informed learning: A pedagogical case study. International Journal of Pedagogies and Learning, 8(2), 106-119. https://doi.org/10.5172/ ijpl.2013.8.2.106

Kaur, A., Young, D., \& Kirkpatrick, R. (2016). English education policy in Thailand: Why the poor results? In R. Kirkpatrick (Ed.), English language education policy in Asia (Language Policy Book 11) (pp. 345-361). Springer International Publishing.

Kirmizi, O. (2012). Research trends in MA ELT programs in Turkey. Procedia-Social and Behavioral Sciences, 46, 4687-4691. https://doi.org/10.1016/j.sbspro.2012.06.319

Li, B., \& Tin, T. B. (2013). Exploring the expectations and perceptions of non-native English-speaking students in master's level TESOL programs. New Zealand Studies in Applied Linguistics, 19(2), 21-35.

Lin, L., \& Cheng, C. (2010). Research trends in selected MA TESOL programs in Taiwan: A preliminary of content analysis of master's theses from 2003-2007. Asian EFL Journal, 12(4), 126-139.

McGrath, I. (2016). Materials evaluation and design for language teaching (2nd ed.). Edinburgh University Press.

Phakiti, A., \& Li, L. (2011). General academic difficulties and reading and writing difficulties among Asian ESL postgraduate students in TESOL at an Australian university. RELC Journal, 42(3), 227-264. https://doi. org/10.1177/0033688211421417

Richards, J. C. (2006). Materials development and research-Making the connection. RELC Journal, 37(1), 5-26. https://doi.org/10.1177/0033688206063470

Richards, J. C. (2008). Second language teacher education today. RELC Journal, 39, 158-177. https://doi. org/10.1177/0033688208092182

Schartner, A., \& Young, T. (2015). Culture shock or love at first sight? Exploring the 'Honeymoon' stage of the international student sojourn. In A. H. Fabricius \& B. Preisler (Eds.), Transcultural interaction and linguistic diversity in higher education (pp. 12-33). Palgrave Macmillan.

Stapleton, P., \& Shao, Q. (2018). A worldwide survey of MATESOL programs in 2014: Patterns and perspectives. 
Language Teaching Research, 22(1), 10-28. https://doi.org/10.1177/1362168816659681

Stapleton, P., \& Shao, Q. (2017). Research in language teaching over two decades: A retrospective of the first 20 volumes of Language Teaching Research. Language Teaching Research, 22(3), 350-369. https://doi. org/10.1177/1362168816688929

Thumvichit, A. (2020). Why and which ELT master's program? Factors influencing student enrollment decisions. The International Journal of Learning in Higher Education, 28(1), 21-35. https://doi.org/10.18848/2327-7955/ CGP/v28i01/21-35

Tomlinson, B. (Ed.). (2008). English language teaching materials: A critical review. Continuum.

Tomlinson, B., \& Masuhara, H. (2017). The complete guide to the theory and practice of materials development for language learning. Wiley Blackwell.

Tseng, C. (2013). Literacy experiences and disciplinary socialisation of second language students in an MA TESOL program [Unpublished doctoral dissertation]. University of California. https://escholarship.org/uc/ item/3fg1w7pw

Tůma, F., \& Pišova, M. (2013). Trends in foreign language didactics research: A thematic analysis of PhD dissertations from the Czech Republic and abroad (2006-2012). The New Educational Review, 34, 125-137.

Wenfeng, W., \& Gao, X. (2008). English language education in China: A review of selected research. Journal of Multilingual and Multicultural Development, 29(5), 380-399. https://doi.org/10.1080/01434630802147908 